\title{
O Imposto sobre Circulação de Mercadorias e Serviços (ICMS) ecológico como instrumento do pagamento por serviços ambientais
}

\author{
The Ecological Goods and Services Circulation Tax (ICMS) as an instrument for payment for \\ environmental services
}

El Impuesto por Circulación de Bienes y Servicios Ecológicos (ICMS) como instrumento de pago de servicios ambientales

\section{Resumo}

O objetivo deste estudo foi analisar a conjuntura atual do ICMS-E nos estados brasileiros e estimar as consequências de sua não aplicabilidade no estado da Paraíba. Através de pesquisa documental e bibliográfica levantou-se os dispositivos legais que instituem e regulamentam o ICMS-E nos Estados brasileiros, tais como os critérios de redistribuição e seus respectivos percentuais de participação. Para estimar o valor não repassado de ICMS-E aos municípios paraibanos utilizou-se o critério populacional, uma vez que os critérios legais não foram regulamentados devido a inconstitucionalidade da lei estadual. Coletou-se a população estimada dos 5 municípios mais populosos do Estado e dos 5 municípios que possuem a menor população para verificar o impacto da não aplicabilidade do ICMS-E nas duas realidades. $\mathrm{Na}$ análise dos dados utilizou-se o método da Proporção Populacional, onde a frequência relativa com que essa categoria se observa na população (p) foi calculado de acordo com Mann (2005). Os resultados mostraram que 17 Estados brasileiros instituíram o ICMS-E sob vários critérios de redistribuição dos recursos, dentre os quais se destacam as unidades de conservação ambiental, mananciais de abastecimento público e tratamento de resíduos sólidos. Na Paraíba, as perdas relativas a não aplicabilidade do ICMS-E no período analisado somam aproximadamente 845 milhões de reais. Desse modo, os 5 municípios mais pobres deixaram de receber em média 430 mil reais/ano. Conclui-se, portanto, que o ICMS-E é um importante mecanismo tributário de gestão ambiental capaz de estimular a conservação do meio ambiente.

Palavras-chave: Pagamento por Serviços Ambientais; ICMS Ecológico; Paraíba.

\begin{abstract}
The objective of this study was to analyze the current situation of the ICMS-E in the Brazilian states and to estimate the consequences of its non-applicability in the state of Paraíba. Through documentary and bibliographic research, the legal provisions that institute and regulate the ICMS-E in Brazilian states were raised, such as the criteria for redistribution and their respective percentage of participation. The population criterion was used to estimate the value of ICMS-E not passed on to the municipalities of Paraíba, since the legal criteria were not regulated due to the unconstitutionality of the state law. The estimated population of the 5 most populous municipalities in the state and the 5 municipalities with the smallest population were collected, to verify the impact of the non-applicability of the ICMS-E in both realities. In the data analysis, the Population Proportion method was used, where the relative frequency with which this category is observed in the population (p) was calculated according to Mann (2005). The results showed that 17 Brazilian states instituted the ICMS-E under various criteria for the redistribution of resources, among which environmental conservation
\end{abstract}


units, public water sources and solid waste treatment stand out. In Paraíba, the losses related to the non-applicability of the ICMS-E in the analyzed period add up to approximately 845 million reais. Thus, the poorest 5 municipalities stopped receiving an average of 430 thousand reais / year. It is concluded, therefore, that the ICMS-E is an important tax mechanism for environmental management capable of stimulating the conservation of the environment.

Keywords: Payment for Environmental Services; Ecological ICMS; Paraíba.

\section{Resumen}

El objetivo de este estudio fue analizar la situación actual del ICMS-E en los estados brasileños y estimar las consecuencias de su no aplicabilidad en el estado de Paraíba. A través de la investigación documental y bibliográfica, se plantearon las disposiciones legales que instituyen y regulan el ICMS-E en los estados brasileños, como los criterios de redistribución y su respectivo porcentaje de participación. Se utilizó el criterio poblacional para estimar el valor del ICMS-E no traspasado a los municipios de Paraíba, ya que los criterios legales no estaban regulados por la inconstitucionalidad de la ley estatal. Se recogió la población estimada de los 5 municipios más poblados del estado y los 5 municipios con menor población, para verificar el impacto de la no aplicabilidad del ICMS-E en ambas realidades. En el análisis de los datos se utilizó el método de Proporción de Población, donde se calculó la frecuencia relativa con la que se observa esta categoría en la población (p) según Mann (2005). Los resultados mostraron que 17 estados brasileños instituyeron el ICMS-E bajo diversos criterios de redistribución de recursos, entre los que destacan las unidades de conservación ambiental, fuentes públicas de agua y tratamiento de residuos sólidos. En Paraíba, las pérdidas relacionadas con la no aplicabilidad del ICMS-E en el período analizado suman aproximadamente 845 millones de reales. Así, los 5 municipios más pobres dejaron de recibir un promedio de 430 mil reales / año. Se concluye, por tanto, que el ICMS-E es un importante mecanismo tributario para la gestión ambiental capaz de estimular la conservación del medio ambiente.

Palabras clave: Pago por servicios ambientales; ICMS ecológico; Paraíba.

\section{Introdução}

Os serviços ecossistêmicos são definidos pelo relatório Millennium Ecosystem Assessment (MEA, 2005) como o conjunto dos benefícios obtidos pelo o homem dos ecossistemas, como o ciclo da água, ciclagem de nutrientes, transferências de energia, regulação de gases e regulação climática.

No Brasil, o Projeto de Lei n 1667 (2007), ainda em tramitação no âmbito federal, define serviços ambientais como funções oferecidas naturalmente pelos ecossistemas para a manutenção de condições ambientais adequadas para a vida no planeta. Segundo o texto do projeto de lei, são diversos os serviços ambientais prestados de forma natural e gratuita pelos ecossistemas para a manutenção de condições ambientais adequadas para a vida no Planeta, citando-se, entre outros: a manutenção da biodiversidade, das paisagens e da diversidade cultural humana, a fixação de carbono, a produção de oxigênio, a purificação do ar, o controle de enfermidades humanas, a moderação das condições climáticas extremas, a manutenção do ciclo hidrológico, a ciclagem de dejetos e nutrientes, a manutenção da fertilidade do solo, o controle de erosão, a dispersão de sementes, a polinização da vegetação, o controle biológico e de pestes etc.

Para Altmann, Souza, Stanton, Cappelli e Stanton (2015) os serviços ecossistêmicos derivam tanto dos processos que ocorrem nos ecossistemas (as funções ecossistêmicas) como dos seus constituintes (organismos e substâncias orgânicas e inorgânicas). Tais serviços são classificados no MEA (2005) como: serviços de provisão - incluindo alimentos, água, madeira e fibras; serviços reguladores - que afetam climas, inundações, doenças, resíduos e a qualidade da água; serviços culturais - que fornecem benefícios recreacionais, estéticos e espirituais; e serviços de suporte - tais como formação do solo, fotossíntese e ciclo de nutrientes.

Guedes e Seehusen (2012), diferenciam o termo serviços ecossistêmicos - expresso no MEA (2005) - do termo serviço ambiental, geralmente usado como sinônimo. Eles afirmam que o primeiro termo possui um caráter mais específico e está associado a ambientes naturais mais preservados e com suas funções ecossistêmicas mais íntegras. Já o segundo termo apresenta um caráter mais genérico servindo para definir tanto os benefícios derivados de ecossistemas naturais como de ambientes alterados pela ação humana. 
Além de está previsto no Projeto de Lei no 1667 (2007), os serviços ambientais estão previstos no Novo Código Florestal Brasileiro, aprovado em 2012 pela Lei Federal no 12.651, bem como na Constituição (1988), onde são denominados de processos ecológicos essenciais. Também tramita no Congresso Nacional desde 2007 o Projeto de Lei 792 (2007), propondo a criação da Política Nacional de Serviços Ambientais (PNSA) (Godecke, Hupffer, \& Chaves 2014).

No Novo Código Florestal Brasileiro, a temática dos serviços ambientais é contemplada dentro da proposta de Pagamento por Serviços Ambientais (PSA) como forma de incentivo à preservação e recuperação do meio ambiente.

Sendo um instrumento econômico de proteção ambiental, o PSA é baseado na Teoria Econômica Neoclássica. No postulado desta teoria econômica, as falhas de mercado expressam-se em externalidades positivas ou negativas, oriundas do processo econômico. O PSA emprega-se para corrigir as falhas de mercado no tocante às externalidades positivas. Ou seja, assim como a legislação brasileira estabelece através do artigo $4^{\circ}$, inciso VII, da Política Nacional do Meio Ambiente (PNMA - Lei $n^{\circ}$ 6.938/81), o princípio do poluidor pagador (baseado nas externalidades negativas do processo produtivo), o PSA tem por base o princípio do protetor recebedor, com base nas externalidades positivas.

A valoração econômica dos bens e serviços ambientais divide-se em valores de uso e valores de não-uso de tais bens e serviços. Os valores de uso podem ser de uso direto ou indireto. Um exemplo de uso direto é o fornecimento de madeira, e de uso indireto, o sequestro de Carbono. Os valores de não-uso são os valores de existência e os valores de legado (biodiversidade, habitat, valores culturais) (Guedes \& Seehusen, 2012).

No âmbito dos valores econômicos de uso indireto, como proteção contra enchentes, tratamento de efluentes, sequestro de Carbono ou mesmo polinização de espécies vegetais, o PSA revela-se como uma ferramenta importante para a preservação dos ecossistemas naturais, podendo ser implementado, por exemplo, através do ICMS Ecológico (ICMS-E). Portanto, o ICMSE é uma política compensatória que representa um incentivo governamental para a manutenção de áreas de preservação ambiental. O recurso deriva do Imposto sobre Circulação de Mercadorias e Serviços (ICMS), instituído pelos artigos 155 e 158 da Constituição Federal (1988).

Face ao exposto, a questão de pesquisa é: qual o panorama atual do ICMS-E no Brasil e quais os impactos financeiros nos municípios paraibanos pela sua não aplicabilidade? Assim, este estudo tem como objetivo analisar a conjuntura atual do ICMS-E nos estados brasileiros e estimar os valores que deveriam ser repassados aos municípios paraibanos. Desse modo, esta pesquisa justifica-se em virtude da importância de se estimular a implantação de políticas públicas voltadas a preservação ambiental, além de ser um trabalho pioneiro na análise das perdas financeiras relativas a não aplicabilidade do ICMS-E no estado da Paraíba.

O artigo divide-se em três seções, além dessa introdução. A primeira apresenta a metodologia de pesquisa. Em seguida, a terceira seção expõe e analisa os resultados deste estudo. E por fim, são realizadas as considerações finais.

\section{Metodologia}

O presente estudo trata-se de uma discussão teórica com base na legislação ambiental brasileira e nas legislações estaduais sobre o ICMS-E, tratando-se de um estudo bibliográfico que reuniu informações e dados necessários a fundamentação sobre o assunto, assim como de uma pesquisa documental para o levantamento dos dados de caráter descritivo, uma vez que sua finalidade é descrever os valores de ICMS-E não repassados aos municípios paraibanos (Gil, 2008).

Para a realização deste estudo, pesquisou-se nas principais leis ambientais estaduais, os dispositivos que instituem e regulamentam o ICMS-E como instrumento de incentivo a proteção ambiental. Foi feito um quadro com os critérios utilizados em lei por cada Unidade da Federação aderente ao ICMS-E para a redistribuição do recurso, e os percentuais de participação de cada critério. 
A receita total de ICMS equivale a receita realizada, ou seja, o valor total arrecadado pelo estado da Paraíba com o imposto ICMS, desconsiderando as rubricas "ICMS - Multas e Juros", "ICMS - Dívida Ativa", "ICMS - Dívida Ativa - Multas e Juros" e "Adicional ICMS - FUNCEP - Principal", por querermos evidenciar apenas o valor principal que seria repassado aos municípios. As parcelas pertencentes aos municípios foram encontradas aplicando a alíquota de $25 \%$ sobre a receita total de ICMS, conforme determina a Constituição Estadual.

Como os critérios de participação dos municípios, bem como os instrumentos de certificação do cumprimento das práticas de preservação ambiental não foram regulamentados devido a decretação de inconstitucionalidade da lei, a única forma de se estimar o valor não repassado de ICMS-E aos municípios é pelo critério populacional, conforme art. $2^{\circ}$, § $1^{\circ}$, da lei 9.600 (2011). De acordo com o dispositivo legal, na hipótese do não enquadramento, de nenhum município nos critérios ecológicos, os recursos previstos seriam distribuídos de forma proporcional à população de cada Município.

Portanto, coletamos a população estimada dos cinco municípios mais populosos da Paraíba, por expressar os grandes montantes que deixaram de ser repassados, e dos cinco municípios que apresentam os menores PIB do estado da Paraíba, por expressar a importância desses recursos para a estrutura financeiras desses municípios.

Sendo assim, foi utilizada uma abordagem qualitativa e quantitativa, através do levantamento e análise de dados secundários, obtidos no Portal da Transparência do estado da Paraíba e no banco de dados do Instituto Brasileiro de Geografia e Estatística (IBGE). Para isso, utilizou-se o método da Proporção Populacional, onde a frequência relativa com que essa categoria se observa na população (p) foi calculado de acordo com Mann (2005) por:

$$
\mathrm{p}=\frac{\mathrm{x}}{\mathrm{N}}
$$

A partir das informações levantadas foram elaboradas tabelas referentes ao período de 2012 a 2019.

\section{Resultados e Discussão}

A redistribuição dos valores referentes ao ICMS-E feita pelos Estados da Federação aos seus respectivos municípios segue critérios que estabelecem a destinação legal do recurso de acordo com o estabelecido em cada legislação estadual específica. A Tabela 1 apresenta os Estados da Federação que instituíram o ICMS-E, suas respectivas leis, os critérios adotados para a distribuição dos recursos e os percentuais de participação de cada critério:

Tabela 1: Legislações Estaduais e os Critérios de Redistribuição do ICMS-E nos Estados.

\section{DESTINAÇÃO DO ICMS ECOLÓGICO}

\begin{tabular}{cccc}
\hline Estado & Lei/Ano & Critério & Participação \\
\hline \multirow{2}{*}{ Paraná } & Lei Complementar $\mathrm{n}^{\circ}$ & Unidades de conservação ambiental & $2,5 \%$ \\
& $59 / 1991$ & Mananciais de abastecimento público de & $2,5 \%$ \\
& & águas & $0,5 \%$ \\
São Paulo & Lei n $8.510 / 1993$ & Unidades de conservação ambiental & $0,5 \%$ \\
& & Reservatórios de água destinados à geração de \\
& & energia elétrica & \\
\hline
\end{tabular}


Minas Gerais Lei $n^{\circ}$ 12.040/1995 Sistema de tratamento de lixo e/ou esgoto sanitário

\begin{tabular}{cccc}
\hline Rondônia & $\begin{array}{c}\text { Lei Complementar }{ }^{\circ} \\
147 / 1996\end{array}$ & Unidades de conservação ambiental & $5 \%$ \\
\hline Amapá & Lei n $^{\circ}$ 322/1996 & Unidades de conservação ambiental & $1,4 \%$ \\
\hline Rio Grande do & Lei n ${ }^{\circ} 11.038 / 1997$ & Unidades de conservação ambiental e áreas & $7 \%$ \\
Sul & inundadas por barragens & $5 \%$ \\
\hline \multirow{2}{*}{ Mato Grosso } & Lei Complementar n ${ }^{\circ}$ & Unidades de conservação ambiental e terras & indígenas \\
\hline
\end{tabular}

Lei Complementar $n^{\circ}$

Mato Grosso do 77/1994, Unidades de conservação ambiental, terras Sul regulamentada pela Lei indígenas e mananciais de abastecimento $\mathrm{n}^{\mathrm{o}} 2.193 / 2000$ e pela público

Lei $2.259 / 2001$

\begin{tabular}{|c|c|c|c|}
\hline \multirow{2}{*}{ Pernambuco } & \multirow{2}{*}{ Lei $n^{\circ} 11.899 / 2000$} & Mananciais de abastecimento público & $1 \%$ \\
\hline & & Unidades de compostagem ou aterro sanitário & $5 \%$ \\
\hline \multirow{5}{*}{ Tocantins } & \multirow{5}{*}{ Lei $n^{\circ} 1.323 / 2002$} & $\begin{array}{c}\text { Unidades de conservação ambiental e terras } \\
\text { indígenas }\end{array}$ & $2 \%$ \\
\hline & & Política municipal de meio ambiente & $2 \%$ \\
\hline & & Controle e combate a queimadas & $2 \%$ \\
\hline & & Conservação dos solos & $2 \%$ \\
\hline & & Saneamento básico e conservação da água & $2 \%$ \\
\hline Acre & Lei $n^{\circ} 1.530 / 2004$ & Unidades de conservação ambiental & $5 \%$ \\
\hline \multirow{3}{*}{ Rio de Janeiro } & \multirow{3}{*}{ Lei $n^{\circ} 5.100 / 2007$} & Unidades de conservação ambiental & $1,13 \%$ \\
\hline & & Qualidade da água & $0,75 \%$ \\
\hline & & $\begin{array}{c}\text { Coleta e disposição adequada de resíduos } \\
\text { sólidos }\end{array}$ & $0,62 \%$ \\
\hline Ceará & $\begin{array}{l}\text { Lei } \mathrm{n}^{\circ} 14.023 / 2007 \text {, } \\
\text { regulamentada pelo } \\
\text { Decreto Estadual n } \\
\quad 29.306 / 2008\end{array}$ & $\begin{array}{l}\text { Índice municipal de qualidade do meio } \\
\text { ambiente }\end{array}$ & $2 \%$ \\
\hline
\end{tabular}




\begin{tabular}{|c|c|c|c|}
\hline Piauí & $\begin{array}{l}\text { Lei Ordinária } \mathrm{n}^{\circ} \\
5.813 / 2008\end{array}$ & $\begin{array}{l}\text { A existência do selo ambiental, desenvolvido } \\
\text { pelo estado para atender os critérios } \\
\text { ambientais da lei específica. }\end{array}$ & $5 \%$ \\
\hline Goiás & $\begin{array}{l}\text { Emenda Constitucional } \\
\qquad n^{\circ} 40 / 2007, \\
\text { regulamentada pela Lei } \\
\text { Complementar } n^{\circ} \\
\text { 90/2011 e pelo decreto } \\
n^{\circ} 8.147 / 2014 .\end{array}$ & $\begin{array}{l}\text { Unidades de conservação ambiental e } \\
\text { mananciais de abastecimento público }\end{array}$ & $5 \%$ \\
\hline Paraíba & lei $n^{\circ} 9.600 / 2011$ & $\begin{array}{l}\text { Unidades de conservação ambiental } \\
\text { Coleta e tratamento de lixo domiciliar }\end{array}$ & $5 \%$ \\
\hline Pará & $\begin{array}{l}\text { Lei } \mathrm{n}^{\circ} 7.638 / 2012 \text {, } \\
\text { regulamentada pelo } \\
\text { Decreto } 775 / 2013 \mathrm{e} \\
\text { pela Portaria SEMA } \\
1.562 / 2013\end{array}$ & $\begin{array}{l}\text { Unidades de conservação ambiental e gestão } \\
\text { ambiental dos municípios }\end{array}$ & $8 \%$ \\
\hline
\end{tabular}

Fonte: Adaptado de Carneiro et al. (2018) e Sousa et al. (2011).

Considerando as maiores economias estaduais dentre as citadas na Tabela 1, como São Paulo, Rio de Janeiro e Minas Gerais, tem-se uma ideia dos efeitos do ICMS-E no âmbito econômico e ambiental em termos de repasse de valores e de preservação ambiental.

No Estado de São Paulo, de acordo com a Secretaria de Infraestrutura e Meio Ambiente (SIMA) (2019), no ano de 2013, só a região do Vale do Ribeira - composta por dez municípios - superou 42 milhões de ICMS-E repassado pelo Estado. A região conta com grandes Unidades de Conservação, e como é menos industrializada e mais agrícola, possui baixo valor adicionado e, consequentemente, reduzido índice de participação (IPM). Assim, os índices de área protegida fazem toda a diferença na arrecadação da região. Os dez municípios da referida região possuem em média 45,2 \% de territórios com áreas protegidas pelo ICMS-E. No Estado de São Paulo como um todo, 186 municípios estão aptos a receber o ICMS-E, sendo que, em 2019, foram repassados R \$ 150.052.977,24 (SIMA, 2019).

O Estado do Rio de Janeiro possui um total de 319 Unidades de Conservação (federais, estaduais e municipais), cujas áreas somadas correspondem a 1.770 .871 hectares (Conti, Irving, \& Antunes, 2015). No período compreendido entre 2009 e 2014 o Estado do Rio de Janeiro arrecadou o montante de R\$ 777.766.335,93 relativo ao ICMS Verde. Considerando o repasse por região administrativa, a Região Metropolitana obteve o maior repasse, com o valor total de R\$ 205.163.246,00, seguida da Região Baixadas Litorâneas com R\$ 133.318.069,00 de repasse. A Região Médio Paraíba aparece em terceiro lugar com um repasse na ordem de $\mathrm{R} \$ 115.978 .855,00$. Da quarta até a oitava posição os repasses variaram entre R\$112 Milhões e R\$ 30 milhões. Cada região destinou o recurso de acordo as peculiaridades de seus municípios (Chueiri, Nascentes, Machado, \& Silva, 2020). 
No Estado de Minas Gerais, do ponto de vista das Unidades de Conservação, os resultados em relação ao aumento da superfície de áreas protegidas incentivadas pelo ICMS Ecológico têm sido contundentes. Em 2007, foram destinados $\mathrm{R} \$ 1.029 .624 .437,00$ aos municípios mineiros, o que representa uma quantia considerável em suas economias. Deste valor, R \$ 41.184.967,00 foram repassados como ICMS Ecológico. Lopes, Lanna e Camargos (1997) relataram que a compensação pelas Unidades de Conservação representou um dos principais efeitos do ICMS Ecológico mineiro, uma vez que vários municípios tiveram sua cota substancialmente aumentada em função desse critério. De acordo com a Fundação João Pinheiro (2020), a transferência bruta do ICMS aos municípios em junho de 2020 foi de R\$1.134.764.896,74.

Na Paraíba, os efeitos da não aplicabilidade do ICMS-E podem ser vistos a seguir na Tabela 2:

Tabela 2: ICMS total, parcelas do ICMS pertencentes aos Municípios e sua distribuição de acordo com o ICMS-E.

\begin{tabular}{cccc}
\hline Exercício & $\begin{array}{c}\text { Receita Total de ICMS } \\
\text { por exercício - 100\% }\end{array}$ & $\begin{array}{c}\text { Parcelas do ICMS } \\
\text { pertencentes aos Municípios - }\end{array}$ & $\begin{array}{c}\text { Percentual que deveria ser } \\
\text { repassado aos munícipios de } \\
\text { ICMS-E: 5\% + 5\% = 10\% }\end{array}$ \\
\hline 2019 & $\mathrm{R} \$ 3.338 .916 .768,98$ & $\mathbf{2 5 \%}$ & $\mathrm{R} \$ 83.472 .919,22$ \\
2018 & $\mathrm{R} \$ 5.342 .258 .525,84$ & $\mathrm{R} \$ 1.335 .564 .631,46$ & $\mathrm{R} \$ 133.556 .463,15$ \\
2017 & $\mathrm{R} \$ 4.920 .425 .030,43$ & $\mathrm{R} \$ 1.230 .106 .257,61$ & $\mathrm{R} \$ 123.010 .625,76$ \\
2016 & $\mathrm{R} \$ 4.573 .644 .648,40$ & $\mathrm{R} \$ 1.143 .411 .162,10$ & $\mathrm{R} \$ 114.341 .116,21$ \\
2015 & $\mathrm{R} \$ 4.350 .042 .623,05$ & $\mathrm{R} \$ 1.087 .510 .655,76$ & $\mathrm{R} \$ 108.751 .065,58$ \\
2014 & $\mathrm{R} \$ 4.246 .314 .260,75$ & $\mathrm{R} \$ 1.061 .578 .565,19$ & $\mathrm{R} \$ 106.157 .856,52$ \\
2013 & $\mathrm{R} \$ 3.761 .794 .197,31$ & $\mathrm{R} \$ 940.448 .549,33$ & $\mathrm{R} \$ 94.044 .854,93$ \\
2012 & $\mathrm{R} \$ 3.237 .438 .081,20$ & $\mathrm{R} \$ 809.359 .520,30$ & $\mathrm{R} \$ 80.935 .952,03$ \\
\hline TOTAL & $\mathrm{R} \$ \mathbf{3 3 . 7 7 0 . 8 3 4 . 1 3 5 , 9 6}$ & $\mathrm{R} \$ \mathbf{8 . 4 4 2 . 7 0 8 . 5 3 3 , 9 9}$ & $\mathbf{R} \mathbf{8 4 4 . 2 7 0 . 8 5 3 , 4 0}$ \\
\hline
\end{tabular}

Fonte: Elaborado a partir dos dados extraídos do Portal da Transparência do estado da Paraíba e IBGE.

O estado da Paraíba arrecadou do ano de 2012 a 2019 aproximadamente 34 bilhões de reais de ICMS. De acordo com o Escritório Técnico de Estudos Econômicos do Nordeste (Etene) (2017), do Banco do Nordeste, com dados do Banco Central e Ministério da Fazenda, a Paraíba chegou a registrar o maior crescimento real (descontada a inflação do período) de arrecadação do ICMS no Nordeste nos cinco primeiros meses de 2017.

Desse montante, a lei $\mathrm{n}^{\circ} 9.600$ (2011) determinava que, dos 25\% das parcelas pertencentes aos Municípios, seriam distribuídos mediante repasse ecológico, de acordo com os seguintes critérios: $70 \%$ na proporção do valor adicionado, nas operações relativas à circulação de mercadorias realizadas em seus respectivos territórios; $20 \%$ equitativo para todos os Municípios; $5 \%$ destinados aos Municípios que abrigarem, na totalidade ou em parte de seu território, uma ou mais unidades de preservação ambiental públicas e/ou privadas, instituídas nos âmbitos municipal, estadual e federal, considerados os critérios de qualidade a serem definidos e aferidos pelo órgão estadual responsável pela gestão ambiental; 5\% destinados aos Municípios que promovam o tratamento de, pelo menos, $50 \%$ (cinquenta por cento) do volume de lixo domiciliar coletado proveniente de seu perímetro urbano (Paraíba, 2011).

Na Paraíba, os municípios que abrigassem, na totalidade ou em parte de seu território, uma ou mais unidades de preservação ambiental públicas e/ou privadas, instituídas nos âmbitos municipal, estadual e federal e que promovessem o tratamento de, pelo menos, $50 \%$ do volume de lixo domiciliar coletado proveniente de seu perímetro urbano receberiam $5 \%$ por cada critério adotado. Considerando o atendimento dos dois critérios ecológicos pelos municípios, o valor total do ICMS-E 
repassado seria de aproximadamente 845 milhões de reais, um valor expressivo que ajudaria as finanças públicas municipais e motivaria a adoção de posturas sustentáveis de preservação do meio ambiente.

O valor exato que cada município receberia não poderia ser evidenciado nesse estudo, pois os critérios de participação dos municípios, bem como os instrumentos de certificação do cumprimento das práticas de preservação ambiental não foram regulamentados. Nesse contexto, e considerando o art. $2^{\circ}, \S 1^{\circ}$, da lei 9.600 (2011), na hipótese do não enquadramento, isolada ou cumulativamente, de nenhum município nos critérios ecológicos, os recursos previstos seriam distribuídos de forma proporcional à população de cada Município. Sendo assim, as cinco cidades mais populosas da Paraíba, conforme dados do IBGE (2020), receberiam desde a promulgação da lei os seguintes valores:

Tabela 3: Valor a ser repassado do ICMS-E segundo o critério populacional definido no art. $2^{\circ}, \S 1^{\circ}$, da lei 9.600 .

\begin{tabular}{ccc}
\hline Cidades & População estimada & Valor total \\
\hline João Pessoa & 817.511 & $\mathrm{R} \$ 170.872 .339,19$ \\
Campina Grande & 411.807 & $\mathrm{R} \$ 86.073 .979,90$ \\
Santa Rita & 137.349 & $\mathrm{R} \$ 28.708 .047,86$ \\
Patos & 108.192 & $\mathrm{R} \$ 22.613 .787,61$ \\
Bayeux & 97.203 & $\mathrm{R} \$ 20.316 .918,04$ \\
\hline
\end{tabular}

Fonte: Elaborado a partir dos dados extraídos do Portal da Transparência do estado da Paraíba e IBGE.

Os municípios de Riacho de Santo Antônio, Curral Velho, Coxixola, Areia de Baraúnas e Parari, que apresentam os menores PIB do estado da Paraíba, conforme os dados do IBGE (2020), receberiam, de acordo com o critério populacional definido no art. $2^{\circ}, \S 1^{\circ}$, da lei 9.600 , os seguintes valores:

Tabela 4: Valor repassado do ICMS-E segundo o critério populacional definido no art. $2^{\circ}$, $§ 1^{\circ}$, da lei 9.600.

\begin{tabular}{ccc}
\hline Cidades & População estimada & Valor \\
\hline Riacho de Santo Antônio & 1.974 & $\mathrm{R} \$ 412.596,28$ \\
Curral Velho & 2.512 & $\mathrm{R} \$ 525.046,53$ \\
Coxixola & 1.935 & $\mathrm{R} \$ 404.444,68$ \\
Areia de Baraúnas & 2.116 & $\mathrm{R} \$ 442.276,46$ \\
Parari & 1.758 & $\mathrm{R} \$ 367.448,97$ \\
\hline
\end{tabular}

Fonte: Elaborado a partir dos dados extraídos do Portal da Transparência do estado da Paraíba e IBGE.

Seja em um município de pequeno ou grande porte, os recursos do ICMS-E são uma importante ferramenta na garantia de um futuro com desenvolvimento e preservação ambiental, minimizando os impactos ambientais gerados pelo crescimento econômico e urbano. Ademais, o ICMS-E é um importante instrumento para a execução das políticas públicas, visto que muitos municípios possuem como única fonte de receita os repasses dos governos federal e estadual.

Infelizmente, o estado da Paraíba não possui o ICMS-E desde a suspensão da eficácia da lei no 9.600 pelo Acórdão proferido na medida cautelar da ação direta de inconstitucionalidade do Tribunal de Justiça da Paraíba, o que representa um atraso nos mecanismos de regulação ambiental e no desenvolvimento sustentável do Estado. Desse modo, a falta de regulamentação do ICMS-E transparece que as ações e práticas tomadas pelo Poder Público não estão totalmente norteadas por 
valores ambientais que levem em consideração a sustentabilidade, a preservação do meio ambiente e a garantia do desenvolvimento sustentável do planeta.

\section{Considerações Finais}

O PSA consiste no aporte de incentivos e recursos, de origem pública e/ou privada, para aqueles que garantem a produção e a oferta do serviço e/ou produto obtido direta ou indiretamente da natureza. No Brasil, alguns estados e municípios instituíram em suas legislações ambientais projetos de PSA com fins de compensação, proteção e preservação ambiental, obtendo bons resultados (Milaré, 2015).

Nesse contexto, o objetivo deste trabalho foi analisar a conjuntura atual do ICMS-E nos estados brasileiros e estimar os valores que deveriam ser repassados aos municípios paraibanos. Diante dos valores e critérios de distribuição apresentados pelos Estados percebe-se a importância de se instituir e se instrumentalizar o ICMS-E como ferramenta de gestão ambiental, uma vez que fica demonstrada a eficiência das políticas compensatórias em um patamar mais elevado do que as políticas de caráter meramente punitivo.

Na Paraíba, a ausência de dispositivo legal que regulamente o ICMS-E atrasa o desenvolvimento sustentável do estado, na medida em que as ações para a preservação e proteção do meio ambiente não são compartilhadas com os municípios. Desse modo, os dados levantados revelaram que aproximadamente 845 milhões de reais poderiam ter sido repassados aos municípios, estimulando-os a adotarem posturas de proteção dos serviços ecossistêmicos e minimizando a falha do mercado em não recompensar os provedores dos benefícios ambientais.

Além de ser um mecanismo de regulação ambiental, o ICMS-E seria uma importante fonte de receitas para os municípios paraibanos, principalmente para aqueles com baixa capacidade de arrecadação e que dependem fortemente de transferências federais e estaduais. Como demostrado, os cinco municípios com os menores PIB do estado receberiam em média 430 mil reais/ano, valor que também ajudaria no equilíbrio das contas públicas municipais.

Portanto, o ICMS-E é um mecanismo do Pagamento por Serviços Ambientais onde todos ganham - meio ambiente, estado e sociedade -, porém a Paraíba perde por não tê-lo em vigor.

Por fim, esta pesquisa apresenta contribuições teóricas e práticas que podem se tornar plausíveis pontos de partida para trabalhos futuros que visem analisar os impactos financeiros em outros municípios cujos estados não aplicam o ICMS-E. Recomenda-se, também, analisar se os municípios que recebem o ICMS-E estão aplicando corretamente estes recursos nas áreas ambientais, fortalecendo, desse modo, as discussões sobre o PSA no âmbito acadêmico.

\section{Referências}

Altmann, A., Souza, L. F. D., Stanton, M. S., Cappelli, S., \& Stanton, M. S. (2015). Manual de apoio à atuação do Ministério Público: pagamento por serviços ambientais. Porto Alegre: Andrefc. http://www. planetaverde. org/arquivos/biblioteca/arquivo_20150528174346_3621.

Carneiro, A. F., Chincoviaki, A. P., \& Vidigal Filho, A. L. (2018). ICMS ecológico nas finanças dos municípios de Rondônia. Brazilian Applied Science Review, 2(2), 458-477.

Castro, B. S., Young, C. E. F., \& de Souza Pereira, V. (2018). Iniciativas Estaduais de Pagamentos por Serviços Ambientais: análise legal e seus resultados. Revibec-Revista Iberoamericana de Economía Ecológica, 44-71.

Chueiri, D. M. A., Nascentes, A. L., Machado, M., \& da Silva, L. D. B. (2020). Icms verde como uma ferramenta de estímulo à gestão ambiental: uma análise das regiões administrtivas do estado do Rio de Janeiro. Revista Valore, 5, 5029.

Constituição da República Federativa do Brasil de 1988. http://www.planalto.gov.br/ccivil_03/constituicao/constituicao.htm

Conti, B. R., de Azevedo Irving, M., \& de Carvalho Antunes, D. (2015). O ICMS-Ecológico e as Unidades de Conservação no Estado do Rio de Janeiro. Desenvolvimento e Meio Ambiente, 35.

Escritório Técnico de Estudos Econômicos do Nordeste (2017). Arrecadação de ICMS aumentou no Nordeste no período janeiro a maio de 2017. Fortaleza: Diário Econômico. https://www.bnb.gov.br/documents/1342439/2128741/239_24_07_2017.pdf/730eb4fa-0a2e-e0f3-5689-f7c0fa8bde9f 
Research, Society and Development, v. 10, n. 3, e16310313262, 2021

(CC BY 4.0) | ISSN 2525-3409 | DOI: http://dx.doi.org/10.33448/rsd-v10i3.13262

Euclydes, A. C. P. (2013). Contradições da política ambiental por meio de incentivos financeiros: os casos do ICMS ecológico e da CFEM nos municípios do Quadrilátero Ferrífero (Minas Gerais, Brasil). Revista Árvore, 37(6), 1083-1092.

Gil, A. C. (2008). Métodos e técnicas de pesquisa social (6. ed.). São Paulo: Atlas.

Godecke, M. V., Hupffer, H. M., \& Chaves, I. R. (2014). O futuro dos Pagamentos por Serviços Ambientais no Brasil a partir do novo Código Florestal. Desenvolvimento e Meio Ambiente, 31 .

Guedes, F. B., \& Seehusen, S. E. (2012). Pagamentos por serviços ambientais na Mata Atlântica: lições aprendidas e desafios. Brasília: MMA, 272.

Instituto Brasileiro de Governança Corporativa. (2020). População residente estimada. Brasília. https://sidra.ibge.gov.br/tabela/6579\#resultado.

Lei Complementar $n^{\circ}$ 9.600, de 21 de dezembro de 2011. Disciplina a participação dos Municípios na arrecadação do Imposto sobre a Circulação de Mercadorias - ICMS, mediante repasse ecológico, e dá outras providências. de https://www.sefaz.pb.gov.br/legislacao/64-leis/icms/614-lei-n-9-600-de-21-de-dezembro-de2011.

Lei n. 12.651 de 25 de maio de 2012. Dispõe sobre a proteção da vegetação nativa; altera as Leis nos 6.938, de 31 de agosto de 1981, 9.393 , de 19 de dezembro de 1996, e 11.428, de 22 de dezembro de 2006; revoga as Leis nos 4.771, de 15 de setembro de 1965, e 7.754, de 14 de abril de 1989, e a Medida Provisória no 2.166-67, de 24 de agosto de 2001; e dá outras providências. Recuperado de http://www.planalto.gov.br/ccivil_03/_ato2011-2014/2012/lei/112651.htm

Lei n. 6.938 de 31 de agosto de 1981. Dispõe sobre a Política Nacional do Meio Ambiente, seus fins e mecanismos de formulação e aplicação, e dá outras providências. http://www.planalto.gov.br/ccivil_03/leis/16938.htm

Lopes, A. L. B., Lanna, M. T., \& Camargos, R. M. F. (1997). A nova lei mineira de repasse de ICMS aos municípios. Anais do Congresso Brasileiro de Engenharia Sanitária e Ambiental, Foz do Iguaçu, PR, Brasil, 20. https://www.redalyc.org/pdf/744/74413024002.pdf

Mann, P. S (2005). Estatística introdutória: usando tecnologia (8. Ed.). Rio de Janeiro: LTC.

Milaré, É. (2015). Direito do ambiente. Thomson Reuters Revista dos Tribunais.

Millennium Ecosystem Assessment (2005). Ecosystem and Human Well-Being: synthesis. Island. https://www.millenniumassessment.org/documents/document.356.aspx.pdf.

Moura, A. S. D. (2015). Imposto sobre Circulação de Mercadorias e Serviços Socioambiental: incentivos institucionais e legislação ambiental no Brasil. Revista de administracao publica, 49(1), 165-188.

Portal da Transparência do Governo da Paraíba (2020). Receita Orçamentária. João Pessoa. https://transparencia.pb.gov.br/receitas/receita-orcamentaria

Projeto de Lei $n^{o} 1667$ da Câmara dos Deputados, de 02 de agosto de 2007. Dispõe sobre a criação do Programa Bolsa Natureza e dá outras providências. https://www.camara.leg.br/proposicoesWeb/fichadetramitacao?idProposicao=360954

Projeto de Lei $n^{\circ} 792$ da Câmara dos Deputados, de 19 de abril de 2007. Dispõe sobre a definição de serviços ambientais e dá outras providências. https://www.camara.leg.br/proposicoesWeb/fichadetramitacao?idProposicao=348783.

Sauquet, A., Marchand, S., \& Féres, J. G. (2014). Protected areas, local governments, and strategic interactions: The case of the ICMS-Ecológico in the Brazilian state of Paraná. Ecological Economics, 107, 249-258.

Secretaria de Infraestrutura e Meio Ambiente (2019). Estimativa de valores, em reais correntes, repassados aos municípios em 2019. São Paulo, https://smastr16.blob.core.windows.net/cpla/2020/02/icms-ecologico_2019.pdf

Sousa, R., Nakajima, N. Y., \& Oliveira, E. (2011). ICMS Ecológico: instrumento de gestão ambiental. Revista Perspectiva, Erechim, 35(129), $27-43$.

Young, C. E., Castro, B., Costa, L., \& Costa, D. S. (2019). O ICSM ecológico como uma política de incentivo dos gastos ambientais municipais. Desenvolvimento em Debate, 7(1), 181-199. 